\title{
Effects of apolipoprotein A5 haplotypes on the ratio of triglyceride to high-density lipoprotein cholesterol and the risk for metabolic syndrome in Koreans
}

Seongwon Cha ${ }^{1 *}$, Hyunjoo Yu ${ }^{1}$, Ah Yeon Park ${ }^{1}$ and Kwang Hoon Song ${ }^{2^{*}}$

\begin{abstract}
Background: Single-nucleotide polymorphisms (SNPS) around the apolipoprotein A5 gene (APOA5) have pleiotropic effects on the levels of triglyceride (TG) and high-density lipoprotein cholesterol (HDL-C). APOA5 SNPS have also been associated with metabolic syndrome (MS). Here, we constructed haplotypes with SNPs spanning APOA5 and ZNF259, which are approximately $1.3 \mathrm{~kb}$ apart, to perform association analyses with the risk for MS and the levels of TG and HDL-C in terms of a TG:HDL-C ratio.

Methods: The effects of three constructed haplotypes (TAA, CGG, and CGA, in the order of rs662799, rs651821, and rs6589566) on the TG:HDL-C ratio and MS were estimated using multiple regression analyses in 2,949 Koreans and in each gender separately (1,082 men and 1,867 women).

Results: The haplotypes, CGG and CGA, were associated with the TG:HDL-C ratio and the risk of MS development in both genders. That is, the minor alleles of the rs662799 and rs651821 in APOA5, irrespective of which allele was present at rs6589566, had the marked effects. Interestingly, a C-G-A haplotype at these three SNPs had the most marked effects on the TG:HDL-C ratio and the risk of MS development in women.
\end{abstract}

Conclusions: We have identified the novel APOA5-ZNF259 haplotype manifesting sex-dependent effects on elevation of the TG:HDL-C ratio as well as the increased risk for MS.

Keywords: APOA5, ZNF259, Haplotype, Triglceride-to-HDL cholesterol ratio, Triglyceride, HDL cholesterol, Metabolic syndrome, Polymorphism

\section{Introduction}

Single-nucleotide polymorphisms (SNPs) in the apolipoprotein A5 gene (APOA5), located on chromosome 11q23 near the $A P O A 1-C 3-A 4$ gene cluster, have pleiotropic effects on changes in the levels of triglycerides (TG) and high-density lipoprotein cholesterol (HDL-C) [1,2]. Recently, a genome-wide association study (GWAS) reported that the minor allele of a SNP, rs964184, has a bivariate effect on TG-elevation and HDL-C-decrease [3]. These

\footnotetext{
* Correspondence: scha@kiom.re.kr; ksong@kiom.re.kr

${ }^{1}$ KM Health Technology Research Group, Medical Research Division, Korea Institute of Oriental Medicine, 1672 Yuseongdae-ro, Yuseong-gu, Daejeon 305-811, Republic of Korea

${ }^{2}$ SME Partnership Center, Korea Institute of Oriental Medicine, 1672

Yuseongdae-ro, Yuseong-gu, Daejeon 305-811, Republic of Korea
}

pleiotropic bivariate associations of $A P O A 5 \mathrm{SNPs}$, in turn, affect the risk for metabolic syndrome (MS) $[1,2,4]$.

Haplotype analyses of association of APOA5 SNPs with lipid levels and risk for MS have focused primarily on variants located within $A P O A 5$ or within the APOA1$C 3-A 4-A 5$ gene cluster [5-12]. In particular, the APOA5 haplotypes, $A P O A 5 * 1$, and $* 2$, and $* 3$, comprised of rs662799 $(-1131 \mathrm{~T}>\mathrm{C}), \quad \mathrm{rs} 3135506(56 \mathrm{C}>\mathrm{G}), \quad$ rs2072560 (IVS3 + 476G>A), and rs2266788 (1259T>C), have been studied for association with lipid levels and MS [5,11-13]. The $A P O A 5 * 2$ haplotype, determined by the minor alleles of rs662799, rs2072560, and rs2266788, has been associated with elevated TG levels and risk for the development of MS [11-13], while the APOA5*3 haplotype, determined 
by the minor allele of rs3135506, has been shown to associate with increased levels of TG $[4,5]$.

However, $A P O A 5$ is adjacent to the zinc finger protein 259 gene (ZNF259; approximately $1.3 \mathrm{~kb}$ downstream of $A P O A 5)$, so that separation of the effects of these closely located genes is difficult. In fact, it is possible that crosstalk between APOA5 and ZNF259 contributes to modulation of plasma TG levels. Although the precise mechanisms associated with this have yet to be determined, research has indicated that APOA5 interaction with proteoglycan-bound lipoprotein lipase and with low-density lipoprotein receptor can reduce plasma TG levels by hydrolysis of TG-rich lipoproteins and by endocytosis of remnant lipoproteins, respectively [14]. ZNF259 encodes a zinc finger protein ZPR1 that binds to the cytoplasmic tyrosine kinase domain of epidermal growth factor receptor (EGFR) in quiescent cells [15]. When mitogens such as EGF disrupt ZPR1 binding by tyrosine phosphorylation of EGFR, ZPR1 is translocated to the nucleus. It has been reported that remnant lipoproteins, among TG-rich lipoproteins, induce EGFR phosphorylation in smooth muscle cells, which results in smooth muscle cell proliferation and atherosclerosis risk [16] and that EGF concentrations in plasma and peripheral blood mononuclear cells associate with lipid concentrations, including TG and HDL-C [17]. Furthermore, the variants exerting effects on TG and HDL-C levels, including rs662799, rs3135506, rs651821, rs2072560, rs2266788, rs6589566, and rs964184, cluster together and are in strong linkage disequilibrium (LD) with each other around the two genes $[3,18,19]$. Therefore, construction of haplotypes with variants spanning both genes is necessary to estimate the precise TG-elevating and HDL-C-lowering effects of APOA5 SNPs in a population.

The current study aimed to determine the effects of haplotypes constructed from variants located around
APOA5 and ZNF259 on the levels of TG and HDL-C, in terms of a ratio of TG to HDL-C, as well as on the risk for MS development. Due to the stronger effects of TG levels on risk of coronary disease in the context of HDL$\mathrm{C}$ levels [20] and the high correlation between the levels of TG and HDL-C, the TG:HDL-C ratio can be a more efficient predictor of the risk for coronary artery diseases [21,22]. In addition, sex-dependent association patterns of these haplotypes were evaluated due to the reported gender effect of $A P O A 5$ haplotypes on MS risk [11].

\section{Results}

\section{Characteristics of recruited subjects and constructed haplotypes}

Characteristics of the recruited subjects are presented in Table 1 and Additional file 1. Age and the prevalence of MS between men and women, as well as the gender proportion according to MS status, were not statistically different, unlike other clinical characteristics. As the linkage of $\operatorname{rs6589566}(\mathrm{A}>\mathrm{G})$ with $\mathrm{rs662799}\left(-1131 \mathrm{~T}>\mathrm{C} ; r^{2}=0.60\right)$ and $\mathrm{rs} 651821\left(-3 \mathrm{~A}>\mathrm{G} ; r^{2}=0.56\right)$ in the studied population was weaker than that in the Asian HapMap population (both $r^{2}=0.80$ ), three rather than two APOA5-ZNF259 haplotypes with an allele frequency $>5 \%$ were constructed, such that TAA (ht1: 68.9\%), CGG (ht2: 20.4\%), and CGA (ht3: 8.57\%) in the order of rs662799, rs651821, and rs6589566 (Figure 1). The genotypes of the three SNPs did not deviate from Hardy-Weinberg equilibrium $(p>0.05)$. Therefore, the genetic effects of these three haplotypes on a ratio of $\log [\mathrm{TG}]$ (log-transformed TG): HDL-C and MS risk were evaluated in Koreans.

\section{Associations of APOA5-ZNF259 haplotypes with TG:HDL-C ratio and MS risk}

Carriage of haplotypes ht 2 or ht 3 , versus the ht 1 haplotype, was significantly associated with increased levels of

Table 1 Characteristics of recruited subjects

\begin{tabular}{lllll}
\hline Characteristic & All $(\mathbf{n}=\mathbf{2 , 9 4 9})$ & Men $(\mathbf{n}=\mathbf{1 , 0 8 2})$ & Women $(\mathbf{n}=\mathbf{1 , 8 6 7})$ & $\boldsymbol{P}^{*}$ \\
\hline Age $(\mathrm{y})$ & $48.20 \pm 15.73$ & $47.87 \pm 15.84$ & $48.39 \pm 15.66$ & 0.628 \\
BMI $\left(\mathrm{kg} / \mathrm{m}^{2}\right)$ & $23.50 \pm 3.339$ & $24.06 \pm 3.219$ & $23.17 \pm 3.364$ & $<0.0001$ \\
WC $(\mathrm{cm})$ & $84.19 \pm 9.890$ & $87.20 \pm 8.867$ & $82.45 \pm 10.03$ & $<0.0001$ \\
SBP $(\mathrm{mmHg})$ & $119.9 \pm 15.72$ & $123.3 \pm 14.86$ & $117.9 \pm 15.88$ & $<0.0001$ \\
DBP $(\mathrm{mmHg})$ & $77.12 \pm 11.26$ & $79.38 \pm 11.08$ & $75.80 \pm 11.16$ & $<0.0001$ \\
FBG $(\mathrm{mg} / \mathrm{dL})$ & $98.91 \pm 28.24$ & $102.2 \pm 29.92$ & $97.00 \pm 27.05$ & $<0.0001$ \\
TG $(\mathrm{mg} / \mathrm{dL})$ & $126.8 \pm 82.83$ & $148.1 \pm 95.48$ & $114.4 \pm 71.70$ & $<0.0001$ \\
HDL-C (mg/dL) & $47.16 \pm 12.35$ & $42.58 \pm 10.81$ & $49.81 \pm 12.41$ & $<0.0001$ \\
Log(TG]:HDL-C & $0.04672 \pm 0.01553$ & $0.05303 \pm 0.01622$ & $0.04306 \pm 0.01386$ & $<0.0001$ \\
MS (\%) & 32.18 & 33.46 & 31.44 & 0.276 \\
\hline
\end{tabular}

Values are indicated as mean \pm standard deviation.

Abbreviations: $B M I$ body mass index, WC waist circumference, SBP systolic blood pressure, DBP diastolic blood pressure, FBG fasting blood glucose, $T G$ triglyceride, $H D L-C$ high-density lipoprotein cholesterol, Log[TG]:HDL-C log-transformed TG:HDL-C ratio, MS metabolic syndrome.

*Wilcoxon rank sum test except chi-squared test for MS. 


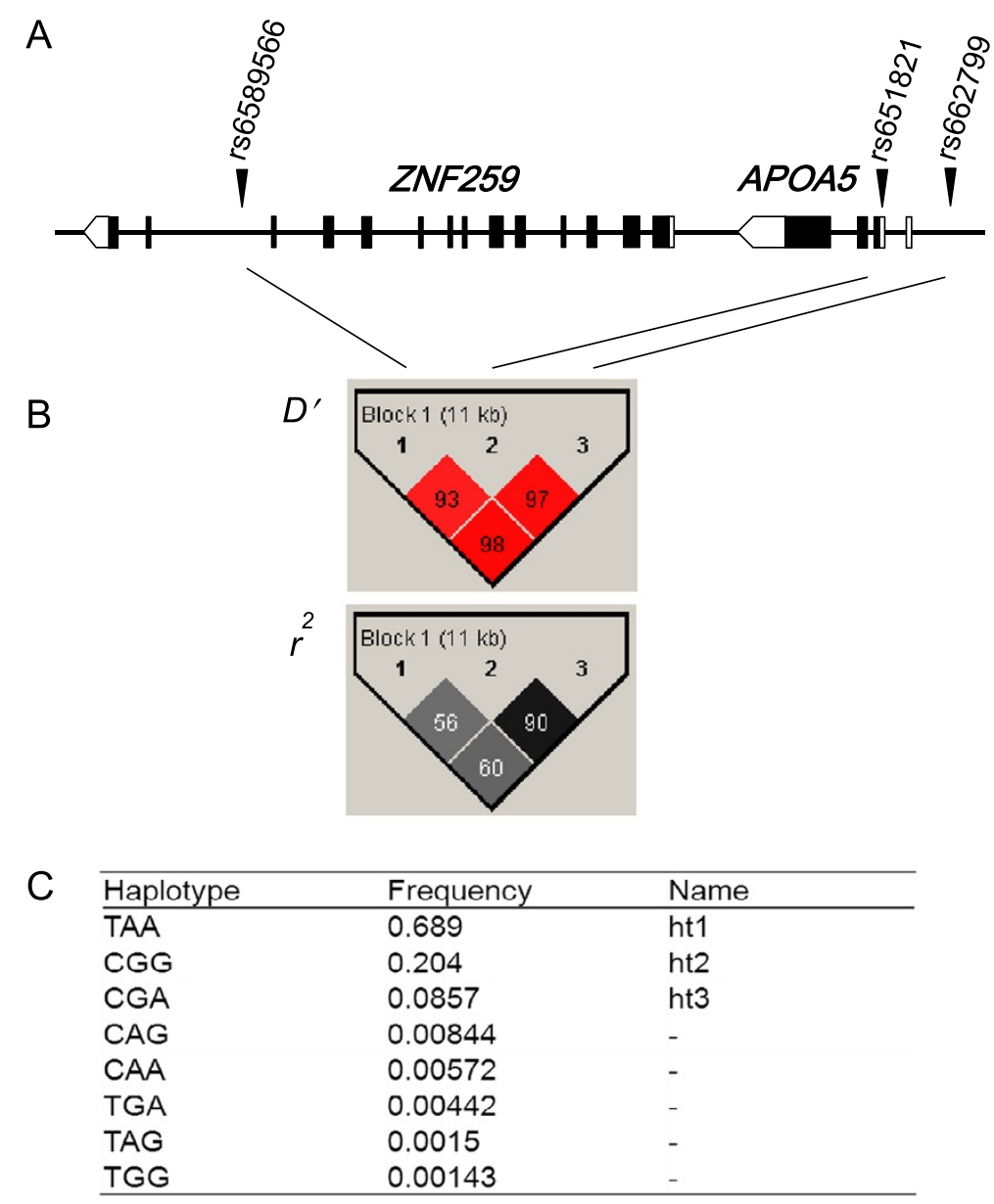

Haplotype: in the order of rs662799 $(-1131 \mathrm{~T}>\mathrm{C})$, rs651821 $(-3 A>G)$, and rs6589566 $(A>G)$

Figure 1 Genetic location, linkage disequilibrium (LD), and haplotypes of single-nucleotide polymorphisms (SNPs). (A) The SNPS rs662799 and rs651821 are respectively located in the promoter and 5' untranslated regions of APOA5 that has 4 exons, whereas SNP rs6589566 is found in intron 12 of ZNF259 that has 14 exons. (B) LD structure of three SNPs: $D^{\prime}$ and $r^{2}$. (C) Haplotype sequence and frequency: haplotypes with frequencies over $5 \%$ were named as ht1, ht2, and ht3.

the $\log [\mathrm{TG}]$ : HDL-C ratio (for ht2 vs ht1, effect $=$ $0.00222,95 \% \mathrm{CI}=0.00130-0.00315$; for ht 3 vs ht1, effect $=0.00460,95 \% \mathrm{CI}=0.00313-0.00607$ ), whereas carriage of the ht 3 haplotype versus the ht 2 haplotype showed only a tendency toward elevating the $\log [\mathrm{TG}]$ : HDL-C ratio (Table 2). When the population was stratified by gender, the genetic effects of the two haplotypes, ht 2 and ht 3 , versus ht 1 haplotype on $\log [\mathrm{TG}]: \mathrm{HDL}-\mathrm{C}$ ratio remained significant, in both genders (for ht2 vs ht1: effect $=0.00328,95 \% \mathrm{CI}=0.00154-0.00502$, in men and effect $=0.00157,95 \% \mathrm{CI}=0.00507-0.00264$ in women; for ht3 vs ht1: effect $=0.00606,95 \% \mathrm{CI}=0.00324$ 0.00888 in men and effect $=0.00391,95 \% \mathrm{CI}=0.00223$ 0.00558 in women). Interestingly, haplotype ht3, with reference to haplotype ht2, was significantly associated with elevation of the $\log [\mathrm{TG}]: \mathrm{HDL}-\mathrm{C}$ ratio only in women (effect $=0.00473,95 \% \mathrm{CI}=0.00130-0.00816$ ). Therefore, the ht3 haplotype showed a sex-dependent association with the $\log [\mathrm{TG}]$ :HDL-C ratio.

The sex-dependent association of the haplotype ht3 was more marked in analyses of the risk of MS (Table 3). The genetic effect of the ht 2 haplotype versus the ht1 haplotype on an increased risk for MS remained significant in men (odds ratio $(\mathrm{OR})=1.50,95 \% \mathrm{CI}=1.16$ 1.94), while the effect of ht3 haplotype versus ht1 haplotype remained significant in women $(\mathrm{OR}=1.41$, $95 \% \mathrm{CI}=1.00-1.97)$. Moreover, association of the ht3 haplotype versus the ht2 haplotype was significant only in women $(\mathrm{OR}=2.67,95 \% \mathrm{CI}=1.25-6.07)$. Taken together, unlike men, women harboring the ht3 haplotype were the most susceptible to MS risk and elevation of the $\log [\mathrm{TG}]: \mathrm{HDL}-\mathrm{C}$. 
Table 2 Association of haplotypes in APOA5 and ZNF259 gene regions with log[TG]:HDL-C ratio

\begin{tabular}{|c|c|c|c|c|c|}
\hline Subject & Hap $1 \& 2$ & $11 / 12 / 22[n]$ & 11/12/22 [mean (sd)] & Effect $(95 \% \mathrm{Cl})^{*}$ & $P^{*}$ \\
\hline \multirow[t]{3}{*}{$\overline{\text { All }}$} & ht1, ht2 & $1,398 / 838 / 115$ & $0.0448(0.0145) / 0.0471(0.0155) / 0.0509(0.0165)$ & $0.00222(0.00130-0.00315)$ & $2.68 \mathrm{E}-06$ \\
\hline & ht1, ht3 & $1,398 / 340 / 17$ & $0.0448(0.0145) / 0.0491(0.0173) / 0.0587(0.0154)$ & $0.00460(0.00313-0.00607)$ & 1.05E-09 \\
\hline & ht2, ht3 & $115 / 123 / 17$ & $0.0509(0.0165) / 0.0537(0.0180) / 0.0587(0.0154)$ & $0.00289(-0.000221-0.00599)$ & 0.0686 \\
\hline \multirow[t]{3}{*}{ Men } & ht1, ht2 & $482 / 325 / 42$ & $0.0508(0.0155) / 0.0528(0.0156) / 0.0609(0.0159)$ & $0.00328(0.00154-0.00502)$ & $2.25 \mathrm{E}-04$ \\
\hline & ht1, ht3 & $482 / 124 / 5$ & $0.0508(0.0155) / 0.0567(0.0176) / 0.0590(0.0125)$ & $0.00606(0.00324-0.00888)$ & 2.83E-05 \\
\hline & ht2, ht3 & $42 / 54 / 5$ & $0.0609(0.0159) / 0.0605(0.0194) / 0.0590(0.0125)$ & $0.00122(-0.00486-0.00731)$ & 0.690 \\
\hline \multirow[t]{3}{*}{ Women } & ht1, ht2 & $916 / 513 / 73$ & $0.0417(0.0128) / 0.0435(0.0143) / 0.0452(0.0140)$ & $0.00157(0.000507-0.00264)$ & 3.84E-03 \\
\hline & ht1, ht3 & $916 / 216 / 12$ & $0.0417(0.0128) / 0.0447(0.0156) / 0.0585(0.0170)$ & $0.00391(0.00223-0.00558)$ & $5.20 \mathrm{E}-06$ \\
\hline & $\mathrm{ht} 2, \mathrm{ht} 3$ & $73 / 69 / 12$ & $0.0452(0.0140) / 0.0484(0.0150) / 0.0585(0.0170)$ & $0.00473(0.00130-0.00816)$ & 7.16E-03 \\
\hline
\end{tabular}

*The effect (beta), 95\% confidence interval (Cl), and $p$-value for Hap 2 versus Hap 1 were estimated by linear regression, after adjusting for age, sex (in all subjects), physical activity (three categories), daily food intake (three categories), clinical history, and medications for hypertension, dyslipidemia, and/or diabetes.

\section{Discussion}

Recent GWAS findings indicated that genes with variants influencing MS per se included the APOA5, ZNF259, and BUD13 homolog); these genes are known to play an important role in lipid metabolism [2]. We also recently reported that the $A P O A 5-1131 \mathrm{~T}>\mathrm{C}$ polymorphism (rs662799) is associated with the risk of MS because of its marked effect on serum TG and HDL-C levels in Korean subjects [1]. The current study has afresh identified that haplotype constructed by SNPs in the closely positioned APOA5-ZNF259 gene region was sex-dependently associated with the ratio of TG to HDL-C and the risk of MS development in Koreans. Specifically, haplotype ht3, viz., C-G-A at rs662799, rs651821, and rs6589566, respectively, was most significantly associated with elevation of the log[TG]:HDL-C ratio, as well as MS susceptibility, in women. We suggest that a causal variant in LD with this APOA5-ZNF259

Table 3 Association of haplotypes in APOA5 and ZNF259 gene regions with metabolic syndrome (MS) risk

\begin{tabular}{|c|c|c|c|c|c|}
\hline Subject & Hap $1 \& 2$ & Subgroup* & $11 / 12 / 22$ [n (\%)] & OR $(95 \% \mathrm{Cl})^{\dagger}$ & $P^{\dagger}$ \\
\hline \multirow[t]{6}{*}{ All } & ht1, ht2 & Control & $988(61.3) / 558(34.6) / 66(4.09)$ & 1 & \\
\hline & & Case & $410(55.5) / 280(37.9) / 49(6.63)$ & $1.33(1.13-1.57)$ & 0.000529 \\
\hline & ht1, ht3 & Control & $988(80.8) / 229(18.7) / 6(0.491)$ & 1 & \\
\hline & & Case & $410(77.1) / 111(20.9) / 11(2.07)$ & $1.41(1.09-1.82)$ & 0.00906 \\
\hline & ht2, ht3 & Control & $66(45.5) / 73(50.3) / 6(4.14)$ & 1 & \\
\hline & & Case & $49(44.5) / 50(45.5) / 11(10.0)$ & $1.31(0.799-2.17)$ & 0.285 \\
\hline \multirow[t]{6}{*}{ Men } & ht1, ht2 & Control & $336(58.9) / 215(37.7) / 19(3.33)$ & 1 & \\
\hline & & Case & $146(52.3) / 110(39.4) / 23(8.24)$ & $1.50(1.16-1.94)$ & 0.00197 \\
\hline & ht1, ht3 & Control & $336(80.2) / 81(19.3) / 2(0.477)$ & 1 & \\
\hline & & Case & $146(76.0) / 43(22.4) / 3(1.56)$ & $1.43(0.950-2.14)$ & 0.0842 \\
\hline & ht2, ht3 & Control & $19(34.5) / 34(61.8) / 2(3.64)$ & 1 & \\
\hline & & Case & $23(50.0) / 20(43.5) / 3(6.52)$ & $0.766(0.356-1.63)$ & 0.489 \\
\hline \multirow[t]{6}{*}{ Women } & ht1, ht2 & Control & $652(62.6) / 343(32.9) / 47(4.51)$ & 1 & \\
\hline & & Case & $264(57.4) / 170(37.0) / 26(5.65)$ & $1.21(0.976-1.50)$ & 0.0813 \\
\hline & ht1, ht3 & Control & $652(81.1) / 148(18.4) / 4(0.498)$ & 1 & \\
\hline & & Case & $264(77.6) / 68(20.0) / 8(2.35)$ & $1.41(1.00-1.97)$ & 0.0463 \\
\hline & ht2, ht3 & Control & $47(52.2) / 39(43.3) / 4(4.44)$ & 1 & \\
\hline & & Case & $26(40.6) / 30(46.9) / 8(12.5)$ & $2.67(1.25-6.07)$ & 0.0142 \\
\hline
\end{tabular}

*Control: subjects with $<3$ MS risk factors ((1) abdominal obesity with waist circumference $\geq 90 \mathrm{~cm}$ for men and $\geq 80 \mathrm{~cm}$ for women, (2) systolic blood pressure $\geq$ $130 \mathrm{mmHg}$, diastolic blood pressure $\geq 85 \mathrm{mmHg}$, or medication for hypertension, (3) TG $\geq 150 \mathrm{mg} / \mathrm{dL}$, (4) HDL-C $<40 \mathrm{mg} / \mathrm{dL}$ for men and $<50 \mathrm{mg} / \mathrm{dL}$ for women, and (5) fasting blood glucose $\geq 110 \mathrm{mg} / \mathrm{dL}$ or medication for hyperglycemia); case: subjects with $\geq 3 \mathrm{MS}$ risk factors.

${ }^{\dagger}$ The odds ratio (OR), 95\% confidence interval $(\mathrm{Cl})$, and $p$-value for Hap 2 versus Hap 1 were estimated by logistic regression, after adjusting for age, sex (in all subjects), physical activity (three categories), daily food intake (three categories), clinical history, and medications for hypertension, dyslipidemia, and/or diabetes. 
haplotype may give rise to TG and HDL-C variations and thus contribute to the risk of MS and coronary artery disease.

In terms of sex-specific influences of the APOA5ZNF259 haplotype on the TG:HDL-C ratio and MS risk, rs6589566, which is located in the ZNF256 intron, will have an important role only in women, such that the major allele of the ZNF256 SNP in combination with the minor alleles of the two APOA5 SNPs can result in greater susceptibility to elevation of the TG:HDL-C ratio and MS risk (Tables 2 and 3). In contrast, in men, the minor alleles of the two SNPs located in the APOA5 locus (rs662799 and rs651821), rather than the rs6589566 allele, will produce the dominant effects. In other words, sexdependent association of the APOA5 SNPs with the TG: HDL-C ratio and MS risk can be determined by using haplotype analyses of the SNPs in the APOA5-ZNF259 locus. These gender effects are different from those previously reported [11], although we also found greater susceptibility to MS with the presence of the ht 2 haplotype in men than in women (Table 3), which is similar to the previously reported gender effect of the $A P O A 5 * 2$ haplotype on MS risk [11].

In a study involving haplotype analysis of a $150-\mathrm{kb}$ region spanning the apolipoprotein gene cluster (APOA1$C 3-A 4-A 5)$, the SNPs in ZNF259 were separated from those in the APOA5 haplotype block [6]. However, in this haplotype analysis, rs1942478 and rs603446 in the ZNF259 intron, were weakly correlated with rs6589566, which is in strong LD with APOA5 SNPs: $r^{2}=0.125$ for rs1942478 and $r^{2}=0.164$ for rs603446 in the Chinese HapMap population [6]. Therefore, the APOA5 haplotype block can be extended to the ZNF259 gene region using rs6589566 and rs964184 located in the ZNF259 intron.

The most obvious weakness of our study is that it is cross-sectional; thus, it would be necessary to confirm the sex-dependent effects of the APOA5-ZNF259 haplotypes on cardiometabolic risk via longitudinal analyses. Although haplotype ht 3 and the TG:HDL-C ratio appear to function in identifying cardiometabolic risk, we cannot conclude that the TG:HDL-C ratio will be as effective in predicting clinical outcomes as a diagnosis of MS. However, despite these weaknesses, the simplicity of the TG:HDL-C ratio approach has obvious advantages: the TG:HDL-C ratio, which relies on two commonly used laboratory measurements, can provide a relatively simple way to identify apparently healthy insulin-resistant persons with increased cardiometabolic risk, since the TG: HDL-C concentration ratio is significantly related to a direct measure of insulin-mediated glucose disposal [23-25].

\section{Conclusions}

In conclusion, we found that haplotypes formed from three SNPs located in APOA5 and ZNF259, viz., rs662799, rs651821, and rs6589566, were significantly associated with susceptibility to MS and elevation of the $\log [\mathrm{TG}]$ : HDL-C ratio, sex-dependently, in Koreans; in particular, the ht3 haplotype was associated with these traits in women. We believe that our findings will help to further develop the clinical utility of the APOA5 haplotypes and the TG:HDL-C ratio as a way to identify cardiometabolic risk.

\section{Methods}

\section{Study population}

All subjects provided written informed consent to participate in the study, and the study was approved by the Institutional Review Board of the Korea Institute of Oriental Medicine.

We recruited 2,949 subjects from 22 oriental medical clinics who were a part of the Korea Constitution Multicenter Study for 6 years since 2006 [1,26]. This population contained 690 patients who had hypertension, dyslipidemia, and/or diabetes. None of the subjects had a history of cancer treatment, thyroid dysfunction, or postmenopausal hormonal therapy. The subjects with MS were defined according to the modified guidelines of National Cholesterol Education Program Adult Treatment Panel III (NCEP ATP III) [27], which stipulated that at least three of the following five criteria had to be met: (1) abdominal obesity with waist circumference $\geq$ $90 \mathrm{~cm}$ for men and $\geq 80 \mathrm{~cm}$ for women [28], (2) systolic blood pressure $\geq 130 \mathrm{mmHg}$, diastolic blood pressure $\geq$ $85 \mathrm{mmHg}$, or medication for hypertension, (3) TG $\geq$ $150 \mathrm{mg} / \mathrm{dL}$, (4) HDL-C $<40 \mathrm{mg} / \mathrm{dL}$ for men and $<50 \mathrm{mg} /$ $\mathrm{dL}$ for women, and (5) fasting blood glucose $\geq 110 \mathrm{mg} / \mathrm{dL}$ or medication for hyperglycemia.

\section{Genotyping of SNPs}

Since TG-elevating and HDL-C-lowering SNPs in APOA5 and ZNF259 (rs662799, rs651821, rs2072560, rs2266788, rs6589566, and rs964184) are strongly correlated with each other in Asian HapMap population $\left(r^{2}>0.8\right)$, we selected three SNPs across the two genes, viz., rs662799 (-1131 of APOA5; one of representative SNPs for $A P O A 5 \% 2$ haplotype), rs651821 ( -3 of $A P O A 5$; a coding SNP in the $5^{\prime}$ untranslated region and one of the representative SNPs for APOA5*2 haplotype), and rs6589566 (a SNP in ZNF259 intron 12). For example, rs6589566 was strongly linked both with rs964184 $\left(D^{\prime}=0.98, r^{2}=0.97\right.$ in Asian HapMap population) and with $\operatorname{rs} 2266788\left(D^{\prime}=1.0\right.$, $r^{2}=0.98$ in Asian HapMap population). The rs3135506 was not selected as a representative SNP for APOA5*3 haplotype, as it is monomorphic in Asian populations.

The genotypes of the three SNPs were determined using two genotyping methods, by using the Affymetrix Genome-Wide Human SNP array 5.0 (Affymetrix, Santa Clara, CA) and unlabeled oligonucleotide probes (UOPs) 
on the given polymorphic nucleotides [29]. The Affymetrix SNP array 5.0 was used for rs6589566 in 882 subjects [30], and the UOP genotyping method was used for the three SNPs (in the rest of the 2,067 subjects for rs6589566). The details of the genotyping method using UOPs (oligonucleotide sequences: Additional file 2) have been described in a previous report [1].

\section{Statistical analysis}

The chi-squared test was used to determine whether the SNPs deviated from Hardy-Weinberg equilibrium in studied population. LD (Lewontin's $D^{\prime}=D /\left|D_{\max }\right|$ and $r^{2}$ ) was obtained from Haploview program, version 4.2 (Daly Lab at the Broad Institute, Cambridge, MA) [31]. Construction of haplotypes of APOA5 SNPs was implemented with Phase, version 2.1, which is a Bayesian algorithm-based program [32,33]. Multiple linear regression analyses were performed for a ratio of $\log [\mathrm{TG}]$ to HDL-C, after adjusting for age, sex, physical activity (three categories), daily food intake (three categories), clinical history of hypertension, dyslipidemia, and/or diabetes, and medications for the three diseases. Multiple logistic regression analyses with the same adjustments, except medications, used in the multiple linear regressions were used for determining the effects of SNPs on MS risk. The $p$-values of $<0.05$ were considered significant. All statistical analyses were performed using R, version 2.15.2 (http://www.r-project.org/).

\section{Additional files}

\section{Additional file 1: Characteristics of the subjects with MS and} control subjects.

Additional file 2: The oligonucleotide sequences of primers and UOPs for 3 SNPs of APOA5 genotyped in Koreans.

\section{Abbreviations \\ APOA5: Apolipoprotein A5; 95\% Cl: 95\% confidence interval; GWAS: Genome- wide association study; HDL-C: High-density lipoprotein cholesterol; MS: Metabolic syndrome; OR: Odds ratio; SNP: Single-nucleotide polymorphism; log[TG]: Log-transformed triglyceride; ZNF259: Zinc finger protein 259}

\section{Competing interests}

The authors declare that they have no competing interests.

\section{Authors' contributions}

SC conceived and designed the study, performed the statistical analyses, interpreted the data, and drafted the manuscript. HY acquired the data, performed the statistical analyses, and helped to draft the manuscript. AYP acquired the data and helped to draft the manuscript. KHS conceived and designed the study, interpreted the data, and drafted the manuscript. All authors approved the final manuscript.

\section{Acknowledgments}

This research was supported by the National Research Foundation of Korea (NRF) funded by the Ministry of Science, ICT \& Future Planning (No. 20062005173).
Received: 2 January 2014 Accepted: 4 March 2014

Published: 12 March 2014

\section{References}

1. Song KH, Cha S, Yu SG, Yu H, Oh SA, Kang NS: Association of Apolipoprotein A5 Gene -1131T>C Polymorphism with the Risk of Metabolic Syndrome in Korean Subjects. Biomed Research International 2013, 2013:585134.

2. Kraja AT, Vaidya D, Pankow JS, Goodarzi MO, Assimes TL, Kullo IJ, Sovio U, Mathias RA, Sun W, Franceschini N, Absher D, Li G, Zhang Q, Feitosa MF, Glazer NL, Haritunians T, Hartikainen AL, Knowles JW, North KE, Iribarren C, Kral B, Yanek L, O'Reilly PF, McCarthy MI, Jaquish C, Couper DJ, Chakravarti A, Psaty BM, Becker LC, Province MA, et al: A bivariate genome-wide approach to metabolic syndrome: STAMPEED consortium. Diabetes 2011, 60:1329-1339.

3. Kathiresan S, Willer CJ, Peloso GM, Demissie S, Musunuru K, Schadt EE, Kaplan L, Bennett D, Li Y, Tanaka T, Voight BF, Bonnycastle LL, Jackson AU, Crawford G, Surti A, Guiducci C, Burtt NP, Parish S, Clarke R, Zelenika D, Kubalanza KA, Morken MA, Scott LJ, Stringham HM, Galan P, Swift AJ, Kuusisto J, Bergman RN, Sundvall J, Laakso M, et al: Common variants at 30 loci contribute to polygenic dyslipidemia. Nat Genet 2009, 41:56-65.

4. Povel CM, Boer JM, Reiling E, Feskens EJ: Genetic variants and the metabolic syndrome: a systematic review. Obes Rev 2011, 12:952-967.

5. Pennacchio LA, Olivier M, Hubacek JA, Krauss RM, Rubin EM, Cohen JC: Two independent apolipoprotein A5 haplotypes influence human plasma triglyceride levels. Hum Mol Genet 2002, 11:3031-3038.

6. Olivier M, Wang X, Cole R, Gau B, Kim J, Rubin EM, Pennacchio LA: Haplotype analysis of the apolipoprotein gene cluster on human chromosome 11. Genomics 2004, 83:912-923.

7. Choi JR, Nam CM, Kang DR, Eom SM, Lee HJ, Park CM, Im JW, Jang Y: DNA polymorphisms and haplotypes of apolipoprotein A5's attribution to the plasma triglyceride levels in Koreans. Yonsei Med J 2007, 48:609-618.

8. Chien KL, Chen MF, Hsu HC, Su TC, Chang WT, Lee CM, Lee YT: Genetic association study of APOA1/C3/A4/A5 gene cluster and haplotypes on triglyceride and HDL cholesterol in a community-based population. Clin Chim Acta 2008, 388:78-83.

9. Matsunaga A, Arishima H, Niimura H, Zhang B, Uehara Y, Ohwaki K, Morita M, Hayashida K, Saku K: Strong linkage disequilibrium and association of $-1131 \mathrm{~T}>\mathrm{C}$ and c.553G $>\mathrm{T}$ polymorphisms of the apolipoprotein A5 gene with hypertriglyceridemia in a Japanese population. Circ J 2007, 71:746-752.

10. Grallert H, Sedlmeier EM, Huth C, Kolz M, Heid IM, Meisinger C, Herder C, Strassburger K, Gehringer A, Haak M, Giani G, Kronenberg F, Wichmann HE, Adamski J, Paulweber B, Illig T, Rathmann W: APOA5 variants and metabolic syndrome in Caucasians. J Lipid Res 2007, 48:2614-2621.

11. Kisfali P, Mohas M, Maasz A, Polgar N, Hadarits F, Marko L, Brasnyo P, Horvatovich K, Oroszlan T, Bagosi Z, Bujtor Z, Gasztonyi B, Rinfel J, Wittmann I, Melegh B: Haplotype analysis of the apolipoprotein A5 gene in patients with the metabolic syndrome. Nutr Metab Cardiovasc Dis 2010, 20:505-511.

12. Qi L, Liu S, Rifai N, Hunter D, Hu FB: Associations of the apolipoprotein A1/C3/A4/A5 gene cluster with triglyceride and HDL cholesterol levels in women with type 2 diabetes. Atherosclerosis 2007, 192:204-210.

13. Pennacchio LA, Olivier M, Hubacek JA, Cohen JC, Cox DR, Fruchart JC, Krauss RM, Rubin EM: An apolipoprotein influencing triglycerides in humans and mice revealed by comparative sequencing. Science 2001, 294:169-173.

14. Forte TM, Shu X, Ryan RO: The ins (cell) and outs (plasma) of apolipoprotein A-V. J Lipid Res 2009, 50(Suppl):S150-155.

15. Galcheva-Gargova Z, Konstantinov KN, Wu IH, Klier FG, Barrett T, Davis RJ. Binding of zinc finger protein ZPR1 to the epidermal growth factor receptor. Science 1996, 272:1797-1802.

16. Kawakami A, Tanaka A, Chiba T, Nakajima K, Shimokado K, Yoshida M: Remnant lipoprotein-induced smooth muscle cell proliferation involves epidermal growth factor receptor transactivation. Circulation 2003, 108:2679-2688.

17. Berrahmoune $H$, Lamont JV, Herbeth B, Lambert D, Masson C, McPhillips M, Fitzgerald PS, Visvikis-Siest S: Association between EGF and lipid concentrations: a benefit role in the atherosclerotic process? Clin Chim Acta 2009, 402:196-198. 
18. Ken-Dror G, Goldbourt U, Dankner R: Different effects of apolipoprotein A5 SNPs and haplotypes on triglyceride concentration in three ethnic origins. J Hum Genet 2010, 55:300-307.

19. Voight BF, Peloso GM, Orho-Melander M, Frikke-Schmidt R, Barbalic M, Jensen MK, Hindy G, Holm H, Ding EL, Johnson T, Schunkert H, Samani NJ, Clarke R, Hopewell JC, Thompson JF, Li M, Thorleifsson G, Newton-Cheh C Musunuru K, Pirruccello JP, Saleheen D, Chen L, Stewart AF, Schillert A, Thorsteinsdottir U, Thorgeirsson G, Anand S, Engert JC, Morgan T, Spertus J, et al: Plasma HDL cholesterol and risk of myocardial infarction: a mendelian randomisation study. Lancet 2012, 380:572-580.

20. Assmann G, Schulte H: Relation of high-density lipoprotein cholesterol and triglycerides to incidence of atherosclerotic coronary artery disease (the PROCAM experience). Prospective Cardiovascular Munster study. Am J Cardiol 1992, 70:733-737.

21. Gaziano JM, Hennekens CH, O'Donnell CJ, Breslow JL, Buring JE: Fasting triglycerides, high-density lipoprotein, and risk of myocardial infarction. Circulation 1997, 96:2520-2525.

22. da Luz PL, Favarato D, Faria-Neto JR Jr, Lemos P, Chagas AC: High ratio of triglycerides to $\mathrm{HDL}$-cholesterol predicts extensive coronary disease. Clinics (Sao Paulo) 2008, 63:427-432.

23. McLaughlin T, Reaven G, Abbasi F, Lamendola C, Saad M, Waters D, Simon J, Krauss RM: Is there a simple way to identify insulin-resistant individuals at increased risk of cardiovascular disease? Am J Cardiol 2005, 96:399-404.

24. Salazar MR, Carbajal HA, Espeche WG, Dulbecco CA, Aizpurua M, Marillet AG Echeverria RF, Reaven GM: Relationships among insulin resistance, obesity, diagnosis of the metabolic syndrome and cardio-metabolic risk. Diab Vasc Dis Res 2011, 8:109-116.

25. McLaughlin T, Abbasi F, Cheal K, Chu J, Lamendola C, Reaven G: Use of metabolic markers to identify overweight individuals who are insulin resistant. Ann Intern Med 2003, 139:802-809.

26. Cha S, Yu H, Kim JY: Bone mineral density-associated polymorphisms are associated with obesity-related traits in Korean adults in a sex-dependent manner. PLoS One 2012, 7:e53013.

27. Expert Panel on Detection E: Treatment of High Blood Cholesterol in A: Executive Summary of The Third Report of The National Cholesterol Education Program (NCEP) Expert Panel on Detection, Evaluation, And Treatment of High Blood Cholesterol In Adults (Adult Treatment Panel III). JAMA 2001, 285:2486-2497.

28. WHO/IASO/IOTF: The Asia-Pacific perspective: redefining obesity and its treatment. Melbourne: Health Communications Australia; 2000.

29. Jeong $\mathrm{S}$, Yu H, Lee Y, Kim JY: SNP genotyping through the melting analysis of unlabelled oligonucleotide applied on dilute PCR amplicon. J Biotechnol 2011, 154:321-325.

30. Kim BY, Jin HJ, Kim JY: Genome-wide association analysis of Sasang constitution in the Korean population. J Altern Complement Med 2012, 18:262-269.

31. Barrett JC, Fry B, Maller J, Daly MJ: Haploview: analysis and visualization of LD and haplotype maps. Bioinformatics 2005, 21:263-265.

32. Stephens M, Scheet P: Accounting for decay of linkage disequilibrium in haplotype inference and missing-data imputation. Am J Hum Genet 2005, 76:449-462

33. Stephens M, Smith NJ, Donnelly P: A new statistical method for haplotype reconstruction from population data. Am J Hum Genet 2001, 68:978-989.

\section{doi:10.1186/1476-511X-13-45}

Cite this article as: Cha et al:: Effects of apolipoprotein A5 haplotypes on the ratio of triglyceride to high-density lipoprotein cholesterol and the risk for metabolic syndrome in Koreans. Lipids in Health and Disease 2014 13:45.

\section{Submit your next manuscript to BioMed Central and take full advantage of:}

- Convenient online submission

- Thorough peer review

- No space constraints or color figure charges

- Immediate publication on acceptance

- Inclusion in PubMed, CAS, Scopus and Google Scholar

- Research which is freely available for redistribution 